\title{
SALURAN PEMASARAN KOPI ROBUSTA (Coffea robusta) DI AGROFORESTRI PEKON AIR KUBANG, KECAMATAN AIR NANINGAN, KABUPATEN TANGGAMUS
}

\author{
Marketing Channels of Robusta Coffee (Coffea robusta) in Agroforestry at Air \\ Kubang Village, Subdistrict Air Naningan, District of Tanggamus \\ Annisa Marchantia Pratiwi, Hari Kaskoyo, Susni Herwanti, Rommy Qurniati \\ Jurusan Kehutanan Fakultas Pertanian Universitas Lampung \\ Jl. Prof. Dr. Sumantri Brojonegoro No. 1 Bandar Lampung 35145 \\ Email : icapratiwi7@gmail.com
}

\begin{abstract}
Agroforestry systems, with products in the form of robusta coffee, can increase income and environmental sustainability. The research objective is to find out the robusta coffee marketing channel. Retrieval of data through interviews with actors or institutions involved, observation, and documentation studies. The data obtained were analyzed descriptively qualitatively about the structure, behavior, and market channels. The results of the study indicate that there are several marketing institutions, namely: farmers, collectors, wholesalers, retailers, and cooperatives. In addition, there are three channels of robusta coffee marketing, namely: (1) farmers to collectors, then wholesalers and retailers, (2) farmers to cooperatives, then retailers, and (3) farmers to cooperatives. The most efficient channel is the third channel, but most farmers choose to sell their coffee to the first channel. This is because of the closer distance to the collecting traders, the lending of money given to farmers by collecting traders, and the absence of special treatment for coffee sold. The market structure formed in coffee marketing is the oligopsonist market, where the price of coffee is determined by large traders. The capacity of cooperatives should be improved by the government in order to compete with collectors, wholesalers, and retailers.
\end{abstract}

Keywords: agroforestry, coffee marketing, marketing agency

\begin{abstract}
ABSTRAK
Sistem agroforestri, dengan produk berupa kopi robusta, dapat meningkatkan pendapatan dan kelestarian lingkungan. Tujuan penelitian untuk mengetahui saluran pemasaran kopi robusta. Pengambilan data melalui wawancara dengan para pelaku atau lembaga yang terlibat, observasi, dan studi dokumentasi. Data yang diperoleh dianalisis secara deskriptif kualitatif mengenai struktur, perilaku, dan saluran pasar. Hasil penelitian menunjukkan ada beberapa lembaga pemasaran, yaitu: petani, pedagang pengumpul, pedagang besar, pengecer, dan koperasi. Selain itu, terdapat tiga saluran pemasaran kopi robusta, yaitu: (1) petani ke pedagang pengumpul, lalu pedagang besar dan pengecer, (2) petani ke koperasi, lalu pengecer, dan (3) petani ke koperasi. Saluran yang paling efisien adalah saluran yang ke-tiga, namun sebagian besar petani memilih menjual hasil panen kopinya ke saluran pertama. Hal ini karena jarak yang lebih dekat ke pedagang pengumpul, adanya pemberian pinjaman uang yang diberikan kepada petani oleh pedagang pengumpul, serta tidak adanya perlakuan khusus terhadap kopi yang dijual. Struktur pasar yang terbentuk dalam pemasaran kopi adalah pasar oligopsoni, dimana harga kopi ditentukan oleh pedagang besar. Kapasitas koperasi sebaiknya ditingkatkan oleh pemerintah agar dapat bersaing dengan pedagang pengumpul, pedagang besar, dan pengecer.
\end{abstract}

Kata kunci: agroforestri, pemasaran kopi, lembaga pemasaran 


\section{PENDAHULUAN}

Pengelolaan hutan di Indonesia dengan sistem agroforestri bertujuan untuk mendukung pembangunan sektor kehutanan (Kholifah et al., 2017). Sistem tersebut dapat menyediakan kebutuhan kayu, meningkatkan produktivitas lahan, dan pendapatan masyarakat (Pratama et al., 2015). Hal ini menjadikan agroforestri sebagai salah satu alternatif dalam menyelesaikan masalah terkait kebutuhan sumberdaya hutan (Widyaningsih \& Diniyati, 2010; Febryano, 2008; Febryano et al., 2009).

Agroforestri kopi di Pekon Air Kubang menghasilkan produk unggulan yaitu kopi robusta. Menurut Dinas Perkebunan Provinsi Lampung (2015) luas areal kopi robusta di Tanggamus yaitu 43.916 ha. dan produksi tanaman kopi robusta sebanyak 27.581 ton, dengan produktivitas 0,63 ton/ha. Petani kopi di daerah Tanggamus memiliki luas lahan antara 0,51,5 ha (Kustyawati et al., 2017). Pemasaran kopi robusta yang dilakukan oleh petani dan lembaga pemasaran dapat meningkatkan pendapatan (Syahruni et al., 2015). Saluran pemasaran merupakan proses penyaluran barang dari produsen kepada konsumen untuk mengukur efisiensi pemasaran, menambah omzet penjualan, dan memudahkan promosi (Praza, 2017).

Semakin banyak lembaga pemasaran yang terlibat mengakibatkan bertambahnya biaya pemasaran, sehingga semakin tinggi pula harga kopi yang dibayarkan konsumen (Lestari et al., 2017). Efisiensi pemasaran kopi dapat ditingkatkan dengan adanya pembentukan badan usaha seperti koperasi; karena semakin sedikit lembaga pemasaran yang terlibat, maka akan semakin efisien (Caesara et al., 2017). Tujuan dari penelitian ini adalah menjelaskan saluran pemasaran produk agroforestri kopi robusta di Pekon Air Kubang.

\section{METODE}

Penelitian dilaksanakan pada Desember 2018 di Pekon Air Kubang, Kecamatan Air Naningan, Kabupaten Tanggamus (Gambar 1). Lokasi dipilih secara sengaja (purposive) dengan pertimbangan Pekon Air Kubang merupakan daerah penghasil kopi yang menggunakan sistem agroforestri. Metode pengambilan sampel menggunakan rumus Slovin, secara Simple Random Sampling sehingga didapatkan jumlah sampel petani sebanyak 55 responden; sedangkan untuk responden lembaga pemasaran lainnya menggukan snowball sampling.

Data primer didapatkan dari wawancara dengan para pelaku atau lembaga yang terlibat dalam pemasaran kopi robusta menggunakan panduan kuisioner, studi dokumentasi, dan observasi langsung. Data sekunder dihimpun melalui penelusuran literatur dan studi pustaka. Data yang dikumpulkan dianalisis secara deskriptif kualitatif yaitu dengan melihat saluran pemasaran, struktur pasar,dan prilaku pasar. Analisis saluran pemasaran dapat dijadikan indikator efisiensi pemasaran dengan membandingkan saluran mana yang paling efisien. 
Jurnal Belantara Vol. 2, No. 2, Agustus 2019 (76-83)

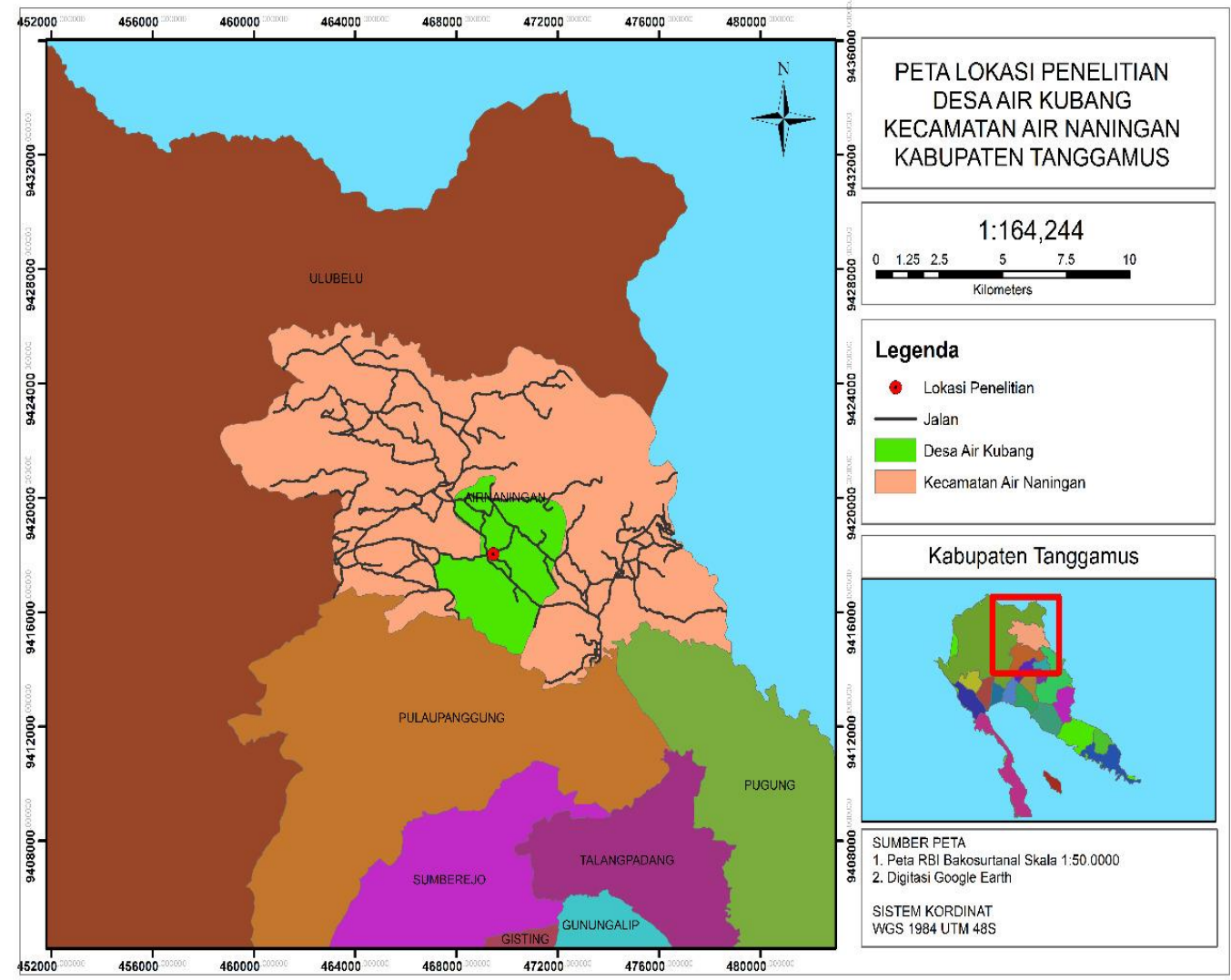

Gambar 1. Peta lokasi penelitian

Figure 1. Map of research location

\section{HASIL dan PEMBAHASAN}

\section{Karakteristik petani responden}

Karakteristik petani responden meliputi umur, tingkat pendidikan, luas lahan yang dikelola, dan kelompok tani. Karakteristik petani dapat dilihat pada Tabel 1.

Tabel 1. Karekteristik petani responden

Table 1. Characteristics of respondent farmers

\begin{tabular}{|c|c|c|c|c|}
\hline No & \multicolumn{2}{|c|}{ Karakteristik } & Jumlah responden (orang) & Persentase \% \\
\hline \multirow[t]{3}{*}{1} & Umur & $12-25$ thn (Remaja) & 0 & 0 \\
\hline & & 26-45 thn (Dewasa) & 36 & 65,45 \\
\hline & & $>46$ thn (Lansia) & 19 & 34,55 \\
\hline \multicolumn{3}{|c|}{ Jumlah } & 55 & 100 \\
\hline \multirow[t]{3}{*}{2} & Tingkat Pendidikan & SD & 33 & 60 \\
\hline & & SMP & 16 & 29,1 \\
\hline & & SMA & 6 & 10.9 \\
\hline \multicolumn{3}{|c|}{ Jumlah } & 55 & 100 \\
\hline \multirow[t]{5}{*}{3} & Luas lahan (ha) & $<1$ & 30 & 54.5 \\
\hline & & $1,1-1,5$ & 6 & 10.9 \\
\hline & & $1,6-2$ & 10 & 18.2 \\
\hline & & $2,1-2,5$ & 0 & 0 \\
\hline & & $>2,6$ & 9 & 16.4 \\
\hline
\end{tabular}


Jurnal Belantara Vol. 2, No. 2, Agustus 2019 (76-83)

\begin{tabular}{rrrrr}
\hline & Jumlah & & 55 & 100 \\
\hline \multicolumn{2}{c}{4 Kelompok tani } & Ya & 15 & 27.3 \\
& & tidak & 40 & 72.7 \\
\hline \multicolumn{2}{c}{ Jumlah } & 55 & 100 \\
\hline \multicolumn{2}{c}{ Sumber : Data primer (2018). } & &
\end{tabular}

Responden yang memiliki umur 26-45 tahun yang berada pada kategori dewasa, menurut Departemen Kesehatan (2009), mendominasi sebanyak 65,45\%. Hal ini menunjukkan bahwa petani responden yang melakukan kegiatan pemasaran kopi lebih banyak berada di usia produktif. Sejalan dengan studi Harwati et al. (2015) produktifitas usaha tani dan pendapatan yang diperoleh akan meningkat apabila umur semakin mendekati usia produktif.

Pendidikan formal tingkat SD lebih banyak telah ditempuh oleh responden yaitu sebesar $60 \%$. Sebagian besar petani masih berpendidikan rendah. Menurut Maryoni (2015) tingkat pendidikan adalah faktor yang mempengaruhi responden dalam hal menerima, menyerap, menerapkan teknologi, informasi, dan pengetahuan dalam melakukan usahatani kopi. Sehingga apabila sumberdaya manusia rendah akan berdampak pada produktivitas petani dan berpengaruh terhadap pendapatan.

Sebanyak 54,5\% petani responden memiliki lahan dengan luas kurang dari 1 ha. Semakin sedikit luas lahan yang diusahakan responden, maka akan semakin rendah pendapatan yang diperoleh. Agroforestri kopi robusta sebagai tanaman utama, ditanam bersama tanaman lainnya pada lahan yang sama seperti tanaman buah-buahan yaitu pisang (Musa acuminate), manggis (Garcinia mangostana), pinang (Pinanga kuhlii), dan durian (Durio zibethinus), serta kayu-kayuan seperti cempaka (Michelia champaca), randu (Ceiba pentandra), afrika (Veronia amygdalina), mahoni (Swietenia macrophylla), dan sengon (Albizia chinensis).

Penerapan agroforestri pada tanaman kopi dengan adanya pohon penaung, dapat mengkonservasi kesuburan tanah, meningkatkan keragaman hayati, dan meningkatkan kesehatan tanaman (Maharani et al., 2013). Penerapan agroforestri juga memberikan jasa lingkungan meliputi pemanfaatan layanan air, perlindungan keanekaragaman hayati, pelestarian dan perlindungan lingkungan, atau penyerapan karbon. HHBK yang dikumpulkan adalah rotan, bambu, madu, getah, buah, dan jamur (Kaskoyo et al., 2014).

Responden petani yang merupakan anggota kelompok tani Tunas Karya 2 hanya sebanyak 27,3\%. Anggota kelompok tani Tunas Karya 2 menjual biji kopi robusta ke koperasi yang ada di Kecamatan Air Naningan. Koperasi meningkatkan kualitas hasil kopi robusta dengan melakukan pembinaan terhadap anggota terutama dalam hal cara berbudidaya yang baik dan ramah lingkungan. Kaskoyo et al. (2017) menyatakan fungsi koperasi adalah untuk menyediakan bahan-bahan dan alat-alat pertanian serta mencoba memasarkan produk-produk hutan.

\section{Saluran pemasaran}

Saluran pemasaran kopi dari petani ke konsumen akhir melibatkan beberapa lembaga pemasaran, yaitu petani, pedagang pengumpul, koperasi, pedagang besar, dan pedagang pengecer (Gambar 2). Menurut Desiana et al. (2017) saluran pemasaran merupakan bagian dari keseluruhan jaringan penghantar nilai pelanggan dari kegiatan pembelian, pengangkutan, penyimpanan, dan penjualan dari petani kopi ke konsumen akhir. Qurniati (2010) menjelaskan bahwa semakin banyak lembaga pemasaran yang terlibat dalam pemasaran dari produsen hingga konsumen akhir, maka memengaruhi panjang pendeknya saluran pemasaran suatu barang. 
Jurnal Belantara Vol. 2, No. 2, Agustus 2019 (76-83)

Saluran pertama

\begin{tabular}{|c|c|c|c|c|}
\hline Petani & Pengumpul & $\begin{array}{l}\text { Pedagang } \\
\text { besar }\end{array}$ & Pengecer 1 & $\begin{array}{l}\text { Konsumen } \\
\text { akhir }\end{array}$ \\
\hline
\end{tabular}

Saluran kedua

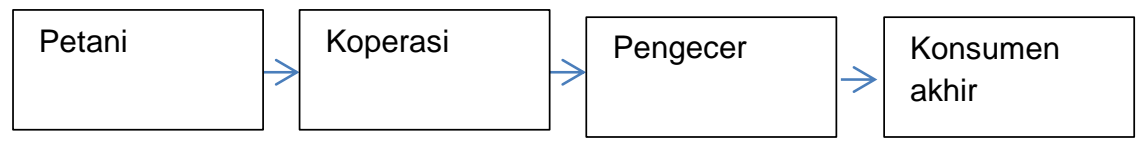

Saluran ketiga

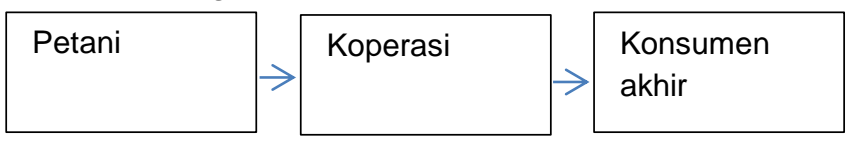

Gambar 2. Saluran pemasaran kopi robusta di Kecamatan Air Naningan, Kabupaten Tanggamus

Figure 2 . Robusta coffee marketing channel in Subdistrict of Air Naningan, Tanggamus District

Saluran pemasaran kopi robusta terdiri atas tiga saluran pemasaran. Saluran pertama digunakan oleh petani kopi sebanyak (72,7\%) dengan total volume penjualan $25.190 \mathrm{~kg}$ dan harga rata-rata penjualan biji kopi robusta dari petani sebesar Rp 19.982 per kg. Pada tingkat pedagang pengumpul, kopi mengalami penyusutan yang disebabkan oleh kadar air kopi sebesar $0,01 \%$ dan penyusutan alat penyimpanan. Kemudian kopi dijual kepada pedagang besar dengan harga rata-rata $\mathrm{Rp} 21.060$ per $\mathrm{kg}$. Kopi mengalami penyusutan sebesar $0,02 \%$ dan penyusutan alat penyimpanan di tingkat pedagang besar. Kopi yang dijual kepada pedagang pengecer sebesar Rp 22.167 per kg. Dari pedagang besar, kopi dijual ke pengecer untuk dijadikan kopi bubuk. Pada tingkat pengecer $1 \mathrm{~kg}$ kopi berkurang $2 \%$ karena proses roasting, penggilingan, dan pengemasan, dan juga adanya penyusutan alat sortasi, alat penggilingan, alat roasting, alat penyimpanan, dan alat pengemasan. Harga jual kopi dari pedagang pengecer sebesar $\mathrm{Rp} 100.000$ per $\mathrm{kg}$. Hal ini sejalan dengan penelitian Marlina et al., (2017) yang menyatakan rantai pemasaran yang panjang menyebabkan petani sangat tergantung pada pedagang besar sebagai penentu harga.

Saluran kedua dan ketiga digunakan oleh petani kopi yang merupakan anggota kelompok tani Tunas Karya $2(27,3 \%)$ dengan total volume penjualan $6.800 \mathrm{~kg}$ dan harga rata-rata penjualan biji kopi robusta dari petani sebesar Rp 23.000 per $\mathrm{kg}$. Pada tingkat koperasi, $1 \mathrm{~kg}$ kopi berkurang $2 \%$ sama seperti pada tingkat pengecer di saluran 1 . Harga jual kopi dari koperasi sebesar Rp 150.000 per kg. Saluran kedua yaitu petani ke koperasi lalu pengecer dan konsumen akhir. Pada tingkat pengecer, kopi tidak mengalami penyusutan karena sudah dalam bentuk kopi bubuk di dalam kemasan. Juliviani et al. (2017) berpendapat bahwa harga jual kopi dari pedagang pengecer sebesar Rp 200.000 per kg. Harga merupakan faktor pendorong petani untuk melakukan kegiatan pemasaran dan salah satu indikator dari rantai pemasaran.

Saluran ketiga merupakan saluran yang paling efisien. Sejalan dengan pernyataan Nurhidayana et al. (2012) semakin pendek saluran maka akan sedikit lembaga pemasaran yang terlibat, sehingga tidak terlalu banyak lembaga pemasaran yang mengambil keuntungan. Namun petani lebih banyak menjual hasil panen kopinya ke saluran pertama. Hal tersebut karena adanya beberapa faktor yaitu jarak penjualan kopi yang lebih dekat ke pedagang pengumpul, pemberian pinjaman uang yang diberikan kepada petani oleh pedagang pengumpul, serta tidak adanya perlakuan khusus terhadap kopi yang dijual. 
Jurnal Belantara Vol. 2, No. 2, Agustus 2019 (76-83)

\section{Struktur pasar}

Struktur pasar dianalisis melalui empat karakteristik yaitu banyaknya jumlah pembeli dan penjual, keadaan produk, syarat keluar masuk pasar berupa modal pengetahuan dan sumber informasi. Karakteristik pertama, yaitu sebanyak 40 responden menjual hasil kopinya ke 5 pedagang pengumpul, 3 pedagang besar, dan 2 pengecer; sedangkan 15 responden petani lainnya memasarkan hasilnya ke koperasi, dan pengecer. Jumlah petani kopi lebih banyak dibandingkan dengan jumlah pedagang, sehingga struktur pasar kopi yang terjadi adalah pasar yang tidak bersaing sempurna atau pasar persaingan oligopsoni. Hal ini sejalan dengan penelitian Wulandari et al. (2018) yang menyatakan pasar oligopsoni terbentuk karena komposisi antara penjual dan pembeli tidak seimbang karena jumlah petani kopi lebih banyak jumlahnya daripada jumlah pedagang.

Karakteristik kedua, petani yang menjual kopinya ke pedagang pengumpul tidak melakukan standarisasi dan grading karena petani menjual secara borongan. Petani yang menjual kopinya ke koperasi melakukan standarisasi dan grading berupa petik biji merah. Pedagang pengumpul dan pedagang besar tidak melakukan standarisasi atau grading. Pada pedagang pengecer dan koperasi dilakukan standarisasi dan grading karena penjualan dilakukan secara eceran atau dijual langsung ke pembeli. Jika kopi memiliki kualitas yang lebih baik dari kopi lainnya, maka kopi tersebut memiliki nilai jual yang lebih tinggi.

Karakteristik ketiga, dilihat dari kemudahan keluar masuk pasar yaitu pada besarnya modal yang dimiliki oleh pedagang dan pengetahuan mengenai produk yang dijual. Pedagang besar membutuhkan modal yang cukup besar, berdasarkan informasi yang didapatkan, modal yang dibutuhkan pedagang besar antara $\mathrm{Rp} 100.000 .000$ sampai $\mathrm{Rp}$ 150.000.000, pedagang pengumpul berkisar antara Rp 8.000.000 sampai Rp 50.000.000, pengecer antara $\mathrm{Rp} 3.000 .000$ sampai $\mathrm{Rp} 50.000 .000$ sedangkan koperasi modal yang dibutuhkan yaitu Rp 50.000.000.

Karakteristik keempat, petani mendapatkan informasi mengenai harga kopi yang berlaku sebelum melakukan kegiatan penjualan. Informasi harga diperoleh dari pedagang besar dan sesama pedagang atau dengan melihat harga kopi di pasaran dunia yang berlaku pada hari tersebut, karena harga kopi mengalami perubahan harga setiap harinya.

\section{Perilaku Pasar}

Pada saluran pertama, 40 responden tidak melakukan tindakan khusus terhadap hasil panennya. Kopi yang telah dipanen diangkut ke rumah petani untuk dijemur. Setiap 1 sampai 2 jam kopi dibolak-balik dengan menggunakan alat seperti garu atau kayu, sehingga keringnya merata selama 10-14 hari bila matahari terik. Namun bila cuaca mendung prosesnya berlangsung hingga 3 minggu sampai kadar airnya mencapai \pm 15 persen. Petani lebih memilih menjual hasil produksinya kepada pedagang pengumpul daripada ke koperasi. Hal ini karena jaraknya yang tidak terlalu jauh dari rumah petani sehingga biaya transportasinya tidak terlalu tinggi dan masih adanya rasa ikatan kekerabatan yang kuat. Beberapa petani juga meminjam uang sebelum panen kopi kepada pedagang pengumpul dan dibayarkan dengan hasil panen kopi petani. Selain itu, tidak ada perlakuan khusus terhadap biji kopi setelah dipanen.

Sebanyak 15 responden menjual hasil panennya ke koperasi dengan melakukan perlakuan khusus. Perlakuan tersebut berupa pemetikan kopi yang telah matang saja, selanjutnya diangkut ke rumah petani untuk dijemur. Penjemuran harus dilapisi oleh terpal, karena biji kopi tidak boleh terkena tanah yang dapat memengaruhi aromanya. Menurut Ardiyani \& Erdiansyah (2012), untuk memperoleh biji kopi yang berkualitas baik sebaiknya biji kopi tidak tercampur dengan biji cacat dan kotoran yang akan merusak mutu kopi.

Pada saat menjual kopi, petani memperoleh informasi harga melalui pedagang pengumpul, karena petani kurang mengetahui informasi mengenai harga yang sedang berlaku. Saat penentuan harga kopi, pedagang pengumpul maupun pedagang besar bertindak sebagai penentu harga dan petani sebagai penerima harga. Setelah terjadi kesepakatan harga kopi ditimbang menggunakan timbangan duduk, dan transaksi pembayaran dilakukan secara tunai. Selanjutnya, dari pedagang pengumpul, kopi dijual ke 
pedagang besar lalu ke pengecer yang terletak di kecamatan yang berbeda. Pada tingkat pengecer dan koperasi biji kopi diolah menjadi kopi bubuk yang siap dikonsumsi, sehingga setelah melalui proses sortasi, penggilingan, roasting, dan pengemasan harga kopi mengalami peningkatan. Hal ini sejalan dengan penelitian Pahlevi et al. (2014) yang menyatakan dengan adanya teknologi seperti mesin giling, mesin pengupas, mesin penggorengan, dan mesin press merupakan kegiatan yang dapat memaksimalkan pendapatan yang dilakukan oleh agroindustri kopi.

\section{KESIMPULAN}

Petani, pedagang pengumpul, pedagang besar, pengecer, dan koperasi merupakan lembaga pemasaran kopi robusta yang terdapat di Pekon Air Kubang. Lembaga-lembaga tersebut membentuk tiga saluran pemasaran, yaitu: (1) petani ke pedagang pengumpul, lalu pedagang besar dan pengecer, (2) petani ke koperasi, lalu pengecer, dan (3) petani ke koperasi. Sebagian besar petani memilih saluran pemasaran yang pertama, walaupun saluran pemasaran ketiga adalah yang paling efisien. Hal ini disebabkan karena jarak yang lebih dekat ke pedagang pengumpul, adanya pemberian pinjaman uang yang diberikan kepada petani oleh pedagang pengumpul, serta tidak adanya perlakuan khusus terhadap kopi yang dijual. Harga kopi ditentukan oleh pedagang besar karena struktur pasarnya merupakan oligopsoni. Pemerintah diharapkan dapat meningkatkan kapasitas koperasi agar dapat bersaing dengan pedagang pengumpul, pedagang besar, dan pengecer.

\section{DAFTAR PUSTAKA}

Ali, M.F., Situmorang, S., \& Murniati, K. (2017). Analisis efisiensi pemasaran kubis di Kecamatan Gisting Kabupaten Tanggamus. Jurnal Ilmu-IImu Agribisnis, 5(3), 258-266.

Ardiyani \& Erdiansyah (2012). Sertifikasi Kopi Berkelanjutan di Indonesia. Jember: Pusat Penelitian Kopi dan Kakao Indonesia.

Caesara, V., Baihaqi, A., \& Usman, M. (2017). Analisis pendapatan dan efisiensi pemasaran biji kopi (green bean) arabika di Kabupaten Bener Meriah. Jurnal IImiah Mahasiswa Pertanian Unsyiah, 2(1), 250-261.

Dinas Perkebunan Provinsi Lampung. (2015). Lampung dalam Angka Tahun 2015. Bandar Lampung: Badan Pusat Statistik Provinsi Lampung.

Departemen Kesehatan Republik Indonesia. (2009). Profil Kesehatan Provinsi Lampung Tahun 2008. Bandar Lampung: Dinas Kesehatan Provinsi Lampung. p. 191.

Desiana, C., Rochdiani, D., \& Pardani, C. (2017). Analisis saluran pemasaran biji kopi robusta (suatu kasus di Desa Kalijaya Kecamatan Banjarsari Kabupaten Ciamis). Jurnal IImiah Mahasiswa Agroinfo Galuh, 4(2), 162-173.

Febryano, I.G. (2008). Analisis finansial agroforestri kakao di lahan hutan negara dan lahan milik. Jurnal Perennial, 4(1), 41-47.

Febryano, I.G., Suharjito, D., \& Soedomo, S. (2009). Pengambilan keputusan pemilihan jenis tanaman dan pola tanam di lahan hutan negara dan lahan milik: Studi kasus di Desa Sungai Langka, Kecamatan Gedong Tataan, Kabupaten Pesawaran, Provinsi Lampung. Forum Pascasarjana, 32(2), 129-141.

Hasyim, A.I. (2012). Pengantar Tataniaga Pertanian. Bandar Lampung: Fakultas Pertanian Universitas Lampung. p. 253.

Harwati, W.M.I., Supardi, S., \& Hastuti, D. (2015). Faktor yang mempengaruhi pendapatan petani jagung (Zea mays L.) (Studi kasus di Desa Sidodadi, Kec. Patean Kab. Kendal). Jurnal Ilmu-IImu Pertanian, 11 (2), 77-86.

Juliaviani, N., Sahara., \& Winandi, R. (2017). Transmisi harga kopi arabika gayo di Provinsi Aceh. Jurnal Agribisnis Indonesia, 5(1), 39-56. 
Kaskoyo, H., Mohammed, A.J., \& Inoue, M. (2014). Present state of community forestry (Hutan Kemasyarakatan/HKM) program in forest and its challenges: Case study in Lampung Province, Indonesia. Journal of Forest Science, 30(1), 15-29.

Kaskoyo, H., Mohammed, A.J., \& Inoue, M. (2017). Impact of community forest program inprotection forest on livelihood outcomes: A case study of Lampung Province, Indonesia. Journal of Suistanable Forestry, 36(3), 250-263.

Kholifah, U.N., Wulandari, C., Santoso, T., \& Kaskoyo, H. (2017). Kontribusi agroforestri terhadap pendapatan petani di Kelurahan Sumber Agung Kecamatan Kemiling Kota Bandar Lampung. Jurnal Sylva Lestari, 5(3), 39-47.

Kustyawati, M.E., Setyani, S., Sugiharto, R., \& Waluyo, S. (2017). Produksi kopi bubuk terintegrasi untuk meningkatkan mutu pada kelompok serba usaha srikandi di Kabupaten Tanggamus. Jurnal Batoboh, 2(1), 45-56.

Lestari, O., Hasyim, A.I., \& Kasymir, E. (2017). Analisis usahatani dan efisiensi pemasaran kopi (coffea sp) di Kecamatan Pulau Panggung Kabupaten Tanggamus. Jurnal IImuIImu Agribisnis, 5(1), 1-8.

Maharani, J.S., Susilo, F.X., Swibawa, I.G., \& Prasetyo, J. (2013). Keterjadian penyakit tersebab jamur pada hama penggerek buah kopi (pbko) di pertanaman kopi agroforestri. Jurnal Agrotek Tropika, 1(1), 86-91.

Marlina, L., Dharmawan, A.H., \& Purnamadewi, Y.L. (2017). Peranan kopi rakyat terhadap perekonomian wilayah Kabupaten Lampung Barat. Jurnal IImu-IImu Agribisnis, 5(3), 292-303.

Maryoni, H. S. (2015). Identifikasi pengaruh luas lahan, biaya pemeliharaan, dan jumlah keluarga terhadap pendapatan petani (studi kasus Desa Kepenuhan Raya). Jurnal Sungkai, 3(2), 34-42.

Nurhidayana., Kuswardani, R.A., \& Siregar, M.A. (2012). Analisis efisiensi pemasaran cabai merah di Kabupaten Batubara. Jurnal Agribisnis Sumatera Utara, 5(1), 28-39.

Pahlevi, R., Zakaria, W.A., \& Kalsum, U. (2014). Analisis kelayakan usaha agroindustri kopi luwak di Kecamatan Balik Bukit Kabupaten Lampung Barat. Jurnal IImu-IImu Agribisnis, 2(1), 48-55.

Pratama, A.R., Yuwono, S.B., \& Hilmanto, R. (2015). Pengelolaan hutan rakyat oleh kelompok pemilik hutan rakyat di Desa Bandar Dalam Kecamatan Sidomulyo Kabupaten Lampung Selatan. Jurnal Sylva Lestari, 3(2), 99-112.

Praza, R. (2017). Identifikasi saluran pemasaran kopi arabika gayo pada CV Gayo Mandiri Coffee Kabupaten Bener Meriah. Jurnal agrifo, 2(1), 58-64.

Qurniati, R. (2010). Buku Ajar Pemasaran Hasil Hutan. Bandar Lampung: Universitas Lampung. p. 115.

Syahruni, T., Hartono, S., Darwanto, D.H., \& Jamhari. (2015). Efisiensi Teknis Usahatani Kopi Arabika di Kabupaten Enrekang. Jurnal Ilmu Pertanian, 18(2), 92-97.

Widyaningsih, T.S. \& Diniyati, D. (2010). Kontribusi ekonomi dan sistem pemasaran hasil hutan rakyat pola wanafarma di Majenang, Cilacap. Jurnal Penelitian Sosial dan Ekonomi Kehutanan, 7(1), 55-71.

Wulandari, D., Qurniati, R., \& Herwanti, S. (2018). Efisiensi pemasaran durian (Durio zibethinus) di desa wisata durian Kelurahan Sumber Agung. Jurnal Sylva Lestari, 6(2), 68-76. 